\title{
Genome sequences hot and cold: a database of organisms with defined optimal growth temperatures
}

\author{
Authors \\ Karla Helena-Bueno ${ }^{1, \#}$, Charlotte R. Brown ${ }^{1, \#,}$ Egor Konyk ${ }^{1}$, Sergey Melnikov ${ }^{1}$
}

\section{Affiliations}

${ }^{1}$ Biosciences Institute, Newcastle University, Newcastle upon Tyne, UK

\# These authors contributed equally to this work.

To whom correspondence should be addressed: sergey.melnikov@ncl.ac.uk

\begin{abstract}
Despite the rapidly increasing number of organisms with sequenced genomes, there is no existing resource that simultaneously contains information about genome sequences and the optimal growth conditions for a given species. In the absence of such a resource, we cannot immediately sort genomic sequences by growth conditions, making it difficult to study how organisms and biological molecules adapt to distinct environments. To address this problem, we have created a database called GSHC (Genome Sequences: Hot, Cold, and everything in between). This database, available at http://melnikovlab.com/gshc, brings together information about the genomic sequences and optimal growth temperatures for 25,324 species, including $\sim 89 \%$ of the bacterial species with known genome sequences. Using this database, it is now possible to readily compare genomic sequences from thousands of species and correlate variations in genes and genomes with optimal growth temperatures, at the scale of the entire tree of life. The database interface allows users to retrieve protein sequences sorted by optimal growth temperature for their corresponding species, providing a tool to explore how organisms, genomes, and individual proteins and nucleic acids adapt to certain temperatures. We hope that this database will contribute to medicine and biotechnology by helping to create a better understanding of molecular adaptations to heat and cold, leading to new ways to preserve biological samples, engineer useful enzymes, and develop new biological materials and organisms with the desired tolerance to heat and cold.
\end{abstract}




\section{Introduction}

Despite significant research efforts to understand how biological molecules adapt to temperature change ${ }^{1-36}$, we are still not able to accurately answer two fundamental questions: What are the most common strategies by which cellular proteins adapt to environmental conditions, such as heat and cold? And can we find a simple and robust approach to alter the thermal tolerance of natural proteins by introducing a minimal number of mutations to the protein sequence?

One challenge in answering these questions stems from the lack of a resource that stores easy-to-use information about the optimal growth conditions of living organisms, together with their genomic data. Currently, there are more than 14,400 genome sequences from representative bacterial species publicly available. In principle, we could use these sequences to study thousands of variants of a given protein, observing how its sequence and structure undergo changes upon transition from cold-adapted bacteria ${ }^{5,8,13,14,20,24,27,37-48}$ to heat-adapted bacteria ${ }^{12,18,28-31,33,49-69}$. In practice, however, it is not immediately possible to organise thousands of organisms (and their genomic sequences) by their optimal growth temperatures, because the corresponding genomic sequences deposited in public repositories (such as NCBI Genomes) lack information about these organisms' optimal growth conditions. Hence, although we have at our disposal genome sequences for thousands of distinct bacteria, eukaryotes, and archaea, we lack a simple tool to sort these organisms (and their genomic sequences) by optimal growth conditions, thereby hindering large-scale studies of molecular and organismal adaptations to temperature. Here, we develop such a resource for scientists and engineers interested in exploring and exploiting molecular adaptations to heat and cold. Using the NCBI database of sequenced genomes as a scaffold, we have created a database in which species with known genome sequences are annotated with information about these species' optimal growth temperature. This database describes the optimal growth temperature of more than 25,000 microorganisms, including $89 \%$ of the representative bacteria whose genome sequences are deposited in the NCBI database.

This new resource makes it possible to retrieve up to 12,354 sequences of a given bacterial protein of interest, sort these sequences by the optimal growth temperature of its corresponding species, and explore how each residue in this protein varies in sequence and conservation upon transition from cold-adapted to heat-adapted organisms. Thus, we provide a tool for large-scale studies of the molecular and organismal adaptations to a specific temperature. 


\section{Database features}

Downloadable lists of species with known genome sequence and together with their optimal growth temperature. Currently, the GSHC database contains information about the optimal growth temperature for 25,324 species. This information is continuously retrieved by web-scraping 23 public repositories of microorganisms (Table 1) and then added to the list of organisms deposited in the NCBI repository of organisms with sequenced genomes. The GSHC site contains the optimal growth temperatures for an organism; however, it does not yet include information about other growth conditions, such as oxygen requirement, $\mathrm{pH}$, pressure, and salt concentration.

Lists of organisms with experimentally defined optimal growth temperatures and a reference to the corresponding genome data can be downloaded from the database. This includes the optimal growth temperature values for 12,265 representative bacteria, 414 representative archaea, and 973 representative eukaryotes. The datasets are updated monthly and are available in .csv format, enabling the species to be sorted by an organism's name, phylogenetic group, genome size, genomic GC-content, number of protein coding genes, and optimal growth temperature. As shown in the example provided for bacterial species (Fig. 1), organisms contained in the datasets include thermophiles and psychrophiles from all major lineages of species, providing an opportunity to study molecular adaptation to heat and cold at the scale of the entire tree of life.

Optimal growth-temperature checker. In addition to the downloadable data, the database user interface allows searching for the optimal growth temperature for a given species. The user can enter a species name in a search window and retrieve the optimal growth temperature for the species of interest if it is present in the database.

Retrieval of protein sequences sorted by optimal growth temperature. In addition to the temperature checker, the database interface allows users to retrieve sequences of their protein of interest arranged by the optimal growth temperature of its corresponding species. The optimal growth temperature is automatically added to the sequence name which allows sequences to be easily aligned, enabling the exploration of how each residue in a protein of interest changes its identity and conservation upon transition from cold-adapted to heat-adapted organisms.

Error and request tracking. To document the rapidly expanding data, most entries in the database are automated, without inspection against published literature. We acknowledge that the optimal growth temperature values for some organisms may contain discrepancies or inaccuracies and therefore encourage users to provide feedback on any unaddressed discrepancies by submitting reports through our feedback tracking system. The submission form allows users to request changes in the database and monitor the progress of each inquiry. 


\section{Applications}

How will this database help researchers to explore molecular mechanisms of thermal adaptation? Below, we propose some example applications:

- First, we can now sort genomes or homologous gene sequences by their optimal growth temperature (and not just by phylogenetic origin), making it possible to explore universal strategies of adaptations to heat and cold, as opposed to idiosyncratic adaptations within each lineage of species. Such studies would have farreaching implications in biotechnology as they can simplify the rational design of biological molecules and organisms with a desired thermal stability 33,61,68,70-75.

- Second, this database simplifies studies of molecular adaptations to temperature within any given range of temperatures. This is important, because to date most studies have focused on extremophiles ${ }^{49,50}$, leaving mostly unexplored how mesophilic organisms adapt to relatively subtle changes in the environment (e.g. temperature increases of a few degrees Celsius as a consequence of climate change $\mathrm{e}^{13,17,23,76}$.

- Third, we can monitor how the identity and conservation of each residue in a protein of interest gradually changes across a range of optimal growth temperatures from $2^{\circ} \mathrm{C}$ to more than $103^{\circ} \mathrm{C}$, simplifying studies of structural constraints $23,46,63,75,77-80$, and finding new ways to engineer useful proteins with a desired optimal thermal tolerance ${ }^{25,70,72,74,75,80,81}$.

- Fourth, this database can help identify model organisms to observe "extremophiles in the making". Currently, the database contains organisms from the same genus that have almost identical sequences for most of their cellular proteins but exhibit dramatically different optimal growth temperatures. For example, the genus Clostridium includes species with an optimal growth temperature ranging from just $5^{\circ} \mathrm{C}$ (Clostridium frigoris) $)^{82}$, to $55^{\circ} \mathrm{C}$ (Clostridium thermobutyricum) $)^{83}$. Comparing species in these genera can provide us with a rare opportunity to observe the natural transformation of mesophiles into extremophiles and gain an understanding of how organisms evolve the ability to tolerate heat and cold through minimal changes in their genomes ${ }^{10,14,33,55,57,69,84}$. These studies are important, as they may help to simplify the design of economically useful microorganisms with the desired thermal tolerance.

\section{Future directions}

We are currently working to expand the database by including additional environmental parameters, such as optimal salt concentration, $\mathrm{pH}$, pressure, and oxygen requirement. We are also testing a new data scraping algorithm to retrieve data not only from repositories of commercially available microorganisms but also from original research papers, to maximise the completeness of our datasets. Finally, we are testing scripts to allow the mapping of temperature-dependent variations in protein sequences to corresponding three-dimensional protein structures that are available in the Protein Data Bank. We hope that in the future our database or similar annotations will be integrated into centralised repositories of genome sequences, such as NCBI, making it possible to explore organismal adaptations to changing environments using the rapidly expanding collection of genomic sequences for both living and extinct species on our planet. 


\section{Figures}
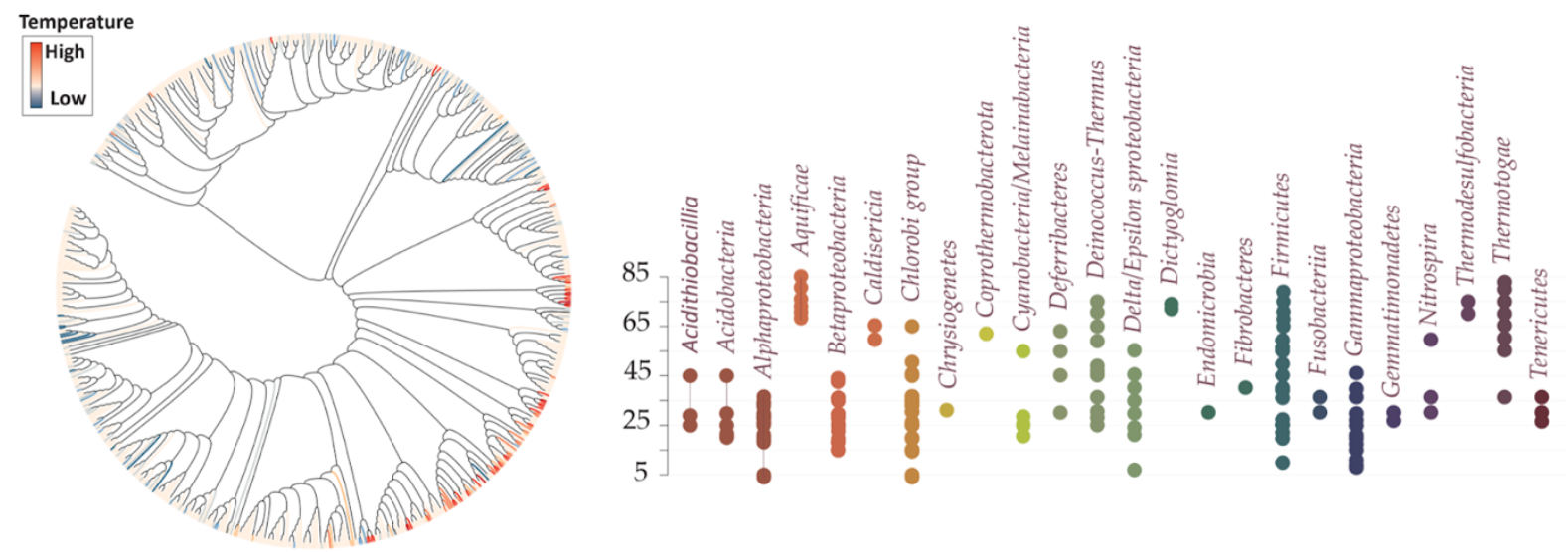

Fig 1 I Bacterial tree of life colour-coded by optimal growth temperatures. a The bacterial tree of life shows representative members of $\mathrm{X}$ bacterial genera, with each organism coloured by the optimal growth temperature. $\mathbf{b}$ Lineages of bacterial species in the database and their corresponding optimal growth temperature. 
bioRxiv preprint doi: https://doi.org/10.1101/2021.12.21.473645; this version posted December $23,2021$. The copyright holder for this preprint (which was not certified by peer review) is the author/funder, who has granted bioRxiv a license to display the preprint in perpetuity. It is made available under aCC-BY-NC-ND 4.0 International license.

\section{Tables}

Table 1 I Websites used for web scraping to collect information about the optimal growth temperatures of microbial organisms.

\begin{tabular}{|c|c|c|}
\hline Database & Database Full Name & URL \\
\hline $\begin{array}{l}\text { ARS } \\
\text { (NRRL) }\end{array}$ & $\begin{array}{l}\text { Agricultural Research Service Culture Collection, National Center for Agricultural } \\
\text { Utilization Research, USA }\end{array}$ & https://nrrl.ncaur.usda.gov/ \\
\hline ATCC & American Type Culture Collection, USA & https://www.atcc.org/ \\
\hline ВССМ & Belgian Coordinated Collections of Microorganisms, Belgium & https://bccm.belspo.be/ \\
\hline BCRC & Bioresources Collection and Research Center, Taiwan & $\underline{\text { https://catalog.bcrc.firdi.org.tw }}$ \\
\hline CABRI & Common Access to Biological Resources and Information & http://www.cabri.org/ \\
\hline CCARM & Culture Collection of Antibiotics Resistant Microbes, UK & https://www.phe-culturecollections.org.uk \\
\hline CCM & Czech Collection of Microorganisms, the Czech Republic & https://www.sci.muni.cz/ccm/ \\
\hline CCUG & Culture Collection, University of Goteborg, Sweden & https://www.ccug.se/ \\
\hline CECT & Spanish Type Culture Collection, Spain & https://www.uv.es/cect/ \\
\hline CICC & China Center of Industrial Culture Collection & http://english.china-cicc.org \\
\hline CIP & Center for Biological Resources of the Institute Pasteur, France & $\underline{\text { https://catalogue-crbip.pasteur.fr }}$ \\
\hline DSMZ & German Collection of Microorganisms and Cell Cultures GmbH, Germany & https://www.dsmz.de \\
\hline GRIN & Agricultural Genetic Resources Information Center, USA & https://www.ars-grin.gov \\
\hline НАМВI & $\begin{array}{l}\text { Culture Collection of Department of Applied Chemistry and Microbiology, } \\
\text { University of Helsinki, Finland }\end{array}$ & https://kotka.luomus.fi/culture/bac \\
\hline $\mathrm{JCM}$ & Japan Collection of Microorganisms (RIKEN Bioresource Center), Japan & https://jcm.brc.riken.jp/en/ordering e \\
\hline KEMB & Korea Environmental Microorganisms Bank, South Korea & https://kemb.or.kr \\
\hline NBIMCC & National Bank for Industrial Microorganisms and Cell Cultures, Bulgaria & https://www.nbimcc.org/en/about.htm \\
\hline NBRC & NITE Biological Resource Center, Japan & https://www.nite.go.jp \\
\hline NCIMB & National Collections of Industrial, Food and Marine Bacteria, UK & https://www.ncimb.com/ \\
\hline NCMA & National Center for Marine Algae and Microbiota (NCMA), USA & https://ncma.bigelow.org/ \\
\hline NCTC & National Collection of Type Cultures, UK & $\begin{array}{l}\text { https://www.phe- } \\
\text { culturecollections.org.uk/ }\end{array}$ \\
\hline NIES & National Institute for Environmental Studies, Japan & https://mcc.nies.go.jp/ \\
\hline VKM & All-Russian Collection of Microorganisms, Russia & $\underline{\text { http://www.vkm.ru }}$ \\
\hline
\end{tabular}




\section{Acknowledgements}

This work was supported by Newcastle University (NUORS 2021 award to K.H-B.), BBSRC UK (4-year PhD studentship BB/T008695/1. to C.R.B.) and the Royal Society UK (RGS $\backslash R 2 \backslash 202003$ to S.M.).

\section{References}

1 Pinney, M. M. et al. Parallel molecular mechanisms for enzyme temperature adaptation. Science 371, doi:10.1126/science.aay2784 (2021).

2 Chursov, A. et al. Specific temperature-induced perturbations of secondary mRNA structures are associated with the cold-adapted temperature-sensitive phenotype of influenza A virus. RNA Biology 9, 1266-1274, doi:10.4161/rna.22081 (2012).

3 Sang, P., Liu, S.-Q. \& Yang, L.-Q. New insight into mechanisms of protein adaptation to high temperatures: a comparative molecular dynamics simulation study of thermophilic and mesophilic subtilisin-like serine proteases. International Journal of Molecular Sciences 21, 3128, doi:10.3390/ijms21093128 (2020).

4 Casanueva, A., Tuffin, M., Cary, C. \& Cowan, D. A. Molecular adaptations to psychrophily: the impact of 'omic' technologies. Trends Microbiol 18, 374-381, doi:10.1016/j.tim.2010.05.002 (2010).

5 Feller, G. \& Gerday, C. Psychrophilic enzymes: hot topics in cold adaptation. Nature Reviews Microbiology 1, 200-208, doi:10.1038/nrmicro773 (2003).

6 Liao, M.-1., Dong, Y.-w. \& Somero, G. N. Thermal adaptation of mRNA secondary structure: stability versus lability. Proceedings of the National Academy of Sciences 118, e2113324118, doi:10.1073/pnas.2113324118 (2021).

7 Kashiwagi, A., Sugawara, R., Sano Tsushima, F., Kumagai, T. \& Yomo, T. Contribution of silent mutations to thermal adaptation of RNA bacteriophage Q $\beta$. Journal of Virology 88, 11459-11468, doi:10.1128/jvi.01127-14 (2014).

8 Pucci, F. \& Rooman, M. Physical and molecular bases of protein thermal stability and cold adaptation. Current Opinion in Structural Biology 42, 117-128, doi:10.1016/j.sbi.2016.12.007 (2017).

9 Lorenz, C., Lünse, C. \& Mörl, M. tRNA modifications: Impact on structure and thermal adaptation. Biomolecules 7, 35, doi:10.3390/biom7020035 (2017).

10 Goncearenco, A., Ma, B.-G. \& Berezovsky, I. N. Molecular mechanisms of adaptation emerging from the physics and evolution of nucleic acids and proteins. Nucleic Acids Research 42, 2879-2892, doi:10.1093/nar/gkt1336 (2014).

11 Fields, P. A., Dong, Y., Meng, X. \& Somero, G. N. Adaptations of protein structure and function to temperature: there is more than one way to 'skin a cat'. Journal of Experimental Biology 218, 1801-1811, doi:10.1242/jeb.114298 (2015).

12 Brininger, C., Spradlin, S., Cobani, L. \& Evilia, C. The more adaptive to change, the more likely you are to survive: protein adaptation in extremophiles. Seminars in Cell E Developmental Biology 84, 158169, doi:https://doi.org/10.1016/j.semcdb.2017.12.016 (2018).

13 Russell, R. J., Gerike, U., Danson, M. J., Hough, D. W. \& Taylor, G. L. Structural adaptations of the cold-active citrate synthase from an Antarctic bacterium. Structure 6, 351-361, doi:10.1016/s09692126(98)00037-9 (1998).

14 Metpally, R. \& Reddy, B. Comparative proteome analysis of psychrophilic versus mesophilic bacterial species: insights into the molecular basis of cold adaptation of proteins. BMC Genomics 10, 11, doi:10.1186/1471-2164-10-11 (2009).

15 Cipolla, A., Delbrassine, F., Da Lage, J.-L. \& Feller, G. Temperature adaptations in psychrophilic, mesophilic and thermophilic chloride-dependent $\alpha$-amylases. Biochimie 94, 1943-1950, doi:10.1016/j.biochi.2012.05.013 (2012).

16 D'Amico, S., Gerday, C. \& Feller, G. Temperature adaptation of proteins: engineering mesophilic-like activity and stability in a cold-adapted $\alpha$-amylase. Journal of Molecular Biololgy 332, 981-988, doi:10.1016/j.jmb.2003.07.014 (2003).

17 Dong, Y. \& Somero, G. N. Temperature adaptation of cytosolic malate dehydrogenases of limpets (genus Lottia): differences in stability and function due to minor changes in sequence correlate with biogeographic and vertical distributions. Journal of Experimental Biology 212, 169-177, doi:10.1242/jeb.024505 (2009). 
18 Berezovsky, I. N. \& Shakhnovich, E. I. Physics and evolution of thermophilic adaptation. Proceedings of the National Academy of Sciences 102, 12742-12747, doi:10.1073/pnas.0503890102 (2005).

19 Zeldovich, K. B., Berezovsky, I. N. \& Shakhnovich, E. I. Protein and DNA sequence determinants of thermophilic adaptation. PLoS Computational Biology 3, e5, doi:10.1371/journal.pcbi.0030005 (2007).

20 Yang, G. et al. Rational engineering of a cold-adapted $\alpha$-amylase from the Antarctic ciliate Euplotes focardii for simultaneous improvement of thermostability and catalytic activity. Applied and Environmental Microbiology 83, AEM.00449-00417, doi:10.1128/aem.00449-17 (2017).

21 De Vendittis, E. et al. Adaptation of model proteins from cold to hot environments involves continuous and small adjustments of average parameters related to amino acid composition. Journal of Theoretical Biology 250, 156-171, doi:https://doi.org/10.1016/j.jtbi.2007.09.006 (2008).

22 Scandurra, R., Condalvi, V., Chiaraluce, R., Politi, L. \& Engel, C., Paul. Protein stability in extremophilic Archaea. Frontiers in Bioscience 5 (2000).

23 Dong, Y.-W., Liao, M.-L., Meng, X.-L. \& Somero, G. N. Structural flexibility and protein adaptation to temperature: molecular dynamics analysis of malate dehydrogenases of marine molluscs. Proceedings of the National Academy of Sciences 115, 1274-1279, doi:10.1073/pnas.1718910115 (2018).

24 Siglioccolo, A., Gerace, R. \& Pascarella, S. "Cold spots" in protein cold adaptation: insights from normalized atomic displacement parameters (B'-factors). Biophysical Chemistry 153, 104-114, doi:https://doi.org/10.1016/j.bpc.2010.10.009 (2010).

25 Cimen, E., Jensen, S. E. \& Buckler, E. S. Building a tRNA thermometer to estimate microbial adaptation to temperature. Nucleic Acids Research 48, 12004-12015, doi:10.1093/nar/gkaa1030 (2020).

26 Liao, M.-L., Somero, G. N. \& Dong, Y.-W. Comparing mutagenesis and simulations as tools for identifying functionally important sequence changes for protein thermal adaptation. Proceedings of the National Academy of Sciences 116, 679-688, doi:10.1073/pnas.1817455116 (2019).

27 Van Petegem, F. et al. The structure of a cold-adapted family 8 xylanase at 1.3 A resolution. Structural adaptations to cold and investgation of the active site. Journal of Biochemistry 278, 7531-7539, doi:10.1074/jbc.M206862200 (2003).

28 Aguilar, C. F. et al. Crystal structure of the $\beta$-glycosidase from the hyperthermophilic archeon Sulfolobus solfataricus: resilience as a key factor in thermostability. Journal of Molecular Biology 271, 789802, doi:10.1006/jmbi.1997.1215 (1997).

29 Smith, C. A., Toogood, H. S., Baker, H. M., Daniel, R. M. \& Baker, E. N. Calcium-mediated thermostability in the subtilisin superfamily: the crystal structure of Bacillus Ak.1 protease at 1.8 A resolution. Journal of Molecular Biology 294, 1027-1040, doi:10.1006/jmbi.1999.3291 (1999).

30 Suvd, D., Fujimoto, Z., Takase, K., Matsumura, M. \& Mizuno, H. Crystal structure of Bacillus stearothermophilus $\alpha$-amylase: possible factors determining the thermostability. Journal of Biochemistry 129, 461-468, doi:10.1093/oxfordjournals.jbchem.a002878 (2001).

31 Chi, Y.-I. et al. Crystal structure of the $\beta$-glycosidase from the hyperthermophile Thermosphaera aggregans: insights into its activity and thermostability. FEBS Letters 445, 375-383, doi:10.1016/s00145793(99)00090-3 (1999).

32 Elias, M., Wieczorek, G., Rosenne, S. \& Tawfik, D. S. The universality of enzymatic rate-temperature dependency. Trends in Biochemical Sciences 39, 1-7, doi:https://doi.org/10.1016/j.tibs.2013.11.001 (2014).

33 van Noort, V. et al. Consistent mutational paths predict eukaryotic thermostability. BMC Evolutionary Biology 13, 7, doi:10.1186/1471-2148-13-7 (2013).

34 Miller, C. et al. Experimental evolution of adenylate kinase reveals contrasting strategies toward protein thermostability. Biophysical Journal 99, 887-896, doi:10.1016/j.bpj.2010.04.076 (2010).

35 Kimura, H., Mori, K., Yamanaka, T. \& Ishibashi, J. Growth temperatures of archaeal communities can be estimated from the guanine-plus-cytosine contents of 16S rRNA gene fragments. Environmental Microbiology Reports 5, 468-474, doi:10.1111/1758-2229.12035 (2013).

36 Melnikov, S., Manakongtreecheep, K. \& Soll, D. Revising the structural diversity of ribosomal proteins across the three domains of life. Molecular Biology and Evolution 35, 1588-1598, doi:10.1093/molbev/msy021 (2018).

37 Feller, G. Molecular adaptations to cold in psychrophilic enzymes. Cellular and Molecular Life Sciences 60, 648-662, doi:10.1007/s00018-003-2155-3 (2003).

38 Mandelman, D. et al. Structural determinants increasing flexibility confer cold adaptation in psychrophilic phosphoglycerate kinase. Extremophiles 23, 495-506, doi:10.1007/s00792-019-01102-x (2019).

39 Russell, N. J. Toward a molecular understanding of cold activity of enzymes from psychrophiles. Extremophiles 4, 83-90, doi:10.1007/s007920050141 (2000). 
40 Aghajari, N., Haser, R., Feller, G. \& Gerday, C. Crystal structures of the psychrophilic $\alpha$-amylase from Alteromonas haloplanctis in its native form and complexed with an inhibitor. Protein Science 7, 564-572, doi:10.1002/pro.5560070304 (1998).

41 D'Amico, S., Gerday, C. \& Feller, G. Structural determinants of cold adaptation and stability in a large protein. Journal of Biological Chemistry 276, 25791-25796, doi:10.1074/jbc.m102741200 (2001).

42 D'Amico, S. et al. Molecular basis of cold adaptation. Philosophical Transactions of the Royal Society of London. Series B: Biological Sciences 357, 917-925, doi:10.1098/rstb.2002.1105 (2002).

43 Cartier, G., Lorieux, F., Allemand, F., Dreyfus, M. \& Bizebard, T. Cold adaptation in DEAD-box proteins. Biochemistry 49, 2636-2646, doi:10.1021/bi902082d (2010).

44 Dassarma, S., Capes, M. D., Karan, R. \& Dassarma, P. Amino acid substitutions in cold-adapted proteins from Halorubrum lacusprofundi, an extremely halophilic microbe from Antarctica. PLoS ONE 8, e58587, doi:10.1371/journal.pone.0058587 (2013).

45 Georlette, D. et al. Some like it cold: biocatalysis at low temperatures. FEMS Microbiology Reviews 28, 25-42, doi:10.1016/j.femsre.2003.07.003 (2004).

46 Kwak, K. J. et al. Structural determinants crucial to the RNA chaperone activity of glycine-rich RNAbinding proteins 4 and 7 in Arabidopsis thaliana during the cold adaptation process. Journal of Experimental Botany 62, 4003-4011, doi:10.1093/jxb/err101 (2011).

47 Shokrollahzade, S., Sharifi, F., Vaseghi, A., Faridounnia, M. \& Jahandideh, S. Protein cold adaptation: role of physico-chemical parameters in adaptation of proteins to low temperatures. Journal of Theoretical Biology 383, 130-137, doi:https://doi.org/10.1016/j.jtbi.2015.07.013 (2015).

48 Zanphorlin, L. M. et al. Oligomerization as a strategy for cold adaptation: structure and dynamics of the GH1 $\beta$-glucosidase from Exiguobacterium antarcticum B7. Scientific Reports 6, 23776, doi:10.1038/srep23776 (2016).

49 Reed, C. J., Lewis, H., Trejo, E., Winston, V. \& Evilia, C. Protein adaptations in archaeal extremophiles. Archaea 2013, 1-14, doi:10.1155/2013/373275 (2013).

50 Cava, F., Hidalgo, A. \& Berenguer, J. Thermus thermophilus as biological model. Extremophiles 13, $213-$ 231, doi:10.1007/s00792-009-0226-6 (2009).

51 Matsuura, Y. et al. Thermodynamics of protein denaturation at temperatures over $100{ }^{\circ} \mathrm{C}$ : CutA1 mutant proteins substituted with hydrophobic and charged residues. Scientific Reports 5, 15545, doi:10.1038/srep15545 (2015).

52 Vetriani, C. et al. Protein thermostability above $100{ }^{\circ} \mathrm{C}$ : a key role for ionic interactions. Proceedings of the National Academy of Sciences of the United States of America 95, 12300-12305, doi:10.1073/pnas.95.21.12300 (1998).

53 Fraser, N. J. et al. Evolution of protein quaternary structure in response to selective pressure for increased thermostability. Journal of Molecular Biology 428, 2359-2371, doi:10.1016/j.jmb.2016.03.014 (2016).

54 Leuenberger, P. et al. Cell-wide analysis of protein thermal unfolding reveals determinants of thermostability. Science 355, doi:10.1126/science.aai7825 (2017).

55 Robinson-Rechavi, M. \& Godzik, A. Structural genomics of Thermotoga maritima proteins shows that contact order is a major determinant of protein thermostability. Structure 13, 857-860, doi:10.1016/j.str.2005.03.011 (2005).

56 Dams, T. et al. The crystal structure of dihydrofolate reductase from Thermotoga maritima: molecular features of thermostability. Journal of Molecular Biology 297, 659-672, doi:10.1006/jmbi.2000.3570 (2000).

57 Robinson-Rechavi, M., Alibés, A. \& Godzik, A. Contribution of electrostatic interactions, compactness and quaternary structure to protein thermostability: lessons from structural genomics of Thermotoga maritima. Journal of Molecular Biology 356, 547-557, doi:10.1016/j.jmb.2005.11.065 (2006).

58 Ma, B.-G., Goncearenco, A. \& Berezovsky, I. N. Thermophilic adaptation of protein complexes inferred from proteomic homology modeling. Structure 18, 819-828, doi:10.1016/j.str.2010.04.004 (2010).

59 Coleman, R. G. \& Sharp, K. A. Thermophilic protein structure adaptation examined with Burial Depth and Travel Depth. Biophysical Journal 96, 584a, doi:10.1016/j.bpj.2008.12.3055 (2009).

60 Rosato, V., Pucello, N. \& Giuliano, G. Evidence for cysteine clustering in thermophilic proteomes. Trends in Genetics 18, 278-281, doi:10.1016/s0168-9525(02)02691-4 (2002).

61 Feng, C. et al. A method for prediction of thermophilic protein based on reduced amino acids and mixed features. Frontiers in Bioengineering and Biotechnology 8, 285, doi:10.3389/fbioe.2020.00285 (2020).

62 Feller, G. Protein stability and enzyme activity at extreme biological temperatures. Journal of Physics: Condensed Matter 22, doi:doi: 10.1088/0953-8984/22/32/323101 (2010). 
63 Zavodszky, P., Kardos, J., Svingor, A. \& Petsko, G. A. Adjustment of conformational flexibility is a key event in the thermal adaptation of proteins. Proceedings of the National Academy of Sciences 95, 7406-7411, doi:10.1073/pnas.95.13.7406 (1998).

64 Kumar, S. \& Nussinov, R. How do thermophilic proteins deal with heat? Cellular and Molecular Life Sciences 58, 1216-1233, doi:10.1007/pl00000935 (2001).

65 Liao, M. L. et al. Heat-resistant cytosolic malate dehydrogenases (cMDHs) of thermophilic intertidal snails (genus Echinolittorina): protein underpinnings of tolerance to body temperatures reaching 55ㄷ․ Journal of Experimental Biology 220, 2066-2075, doi:10.1242/jeb.156935 (2017).

66 Fang, X. W. et al. The thermodynamic origin of the stability of a thermophilic ribozyme. Proceedings of the National Academy of Sciences 98, 4355-4360, doi:10.1073/pnas.071050698 (2001).

67 Kumar, S., Tsai, C.-J. \& Nussinov, R. Factors enhancing protein thermostability. Protein Engineering, Design and Selection 13, 179-191, doi:10.1093/protein/13.3.179 (2000).

68 Yang, J. et al. Identification and thermoadaption engineering of thermostability conferring residue of deep sea bacterial $\alpha$-amylase AMY121. Journal of Molecular Catalysis 126, 56 - 63 (2016).

69 Meruelo, A. D., Han, S. K., Kim, S. \& Bowie, J. U. Structural differences between thermophilic and mesophilic membrane proteins. Protein Science 21, 1746-1753, doi:10.1002/pro.2157 (2012).

70 Furukawa, R., Toma, W., Yamazaki, K. \& Akanuma, S. Ancestral sequence reconstruction produces thermally stable enzymes with mesophilic enzyme-like catalytic properties. Scientific Reports 10, doi:10.1038/s41598-020-72418-4 (2020).

71 Pezeshgi Modarres, H., Mofrad, M. R. \& Sanati-Nezhad, A. ProtDataTherm: a database for thermostability analysis and engineering of proteins. PLoS ONE 13, e0191222, doi:10.1371/journal.pone.0191222 (2018).

72 Xu, Z., Cen, Y.-K., Zou, S.-P., Xue, Y.-P. \& Zheng, Y.-G. Recent advances in the improvement of enzyme thermostability by structure modification. Critical Reviews in Biotechnology 40, 83-98, doi:10.1080/07388551.2019.1682963 (2020).

73 Bashirova, A. et al. Disulfide bond engineering of an endoglucanase from Penicillium verruculosum to improve its thermostability. International Journal of Molecular Sciences 20, 1602, doi:10.3390/ijms20071602 (2019).

74 Pinto, G. P., Corbella, M., Demkiv, A. O. \& Kamerlin, S. C. L. Exploiting enzyme evolution for computational protein design. Trends in Biochemical Sciences, doi:10.1016/j.tibs.2021.08.008 (2021).

75 Lee, C. F., Makhatadze, G. I. \& Wong, K. B. Effects of charge-to-alanine substitutions on the stability of ribosomal protein L30e from Thermococcus celer. Biochemistry 44, 16817-16825, doi:10.1021/bi0519654 (2005).

76 Cavicchioli, R. et al. Scientists' warning to humanity: microorganisms and climate change. Nature Reviews Microbiology 17, 569-586, doi:10.1038/s41579-019-0222-5 (2019).

77 Sočan, J., Purg, M. \& Åqvist, J. Computer simulations explain the anomalous temperature optimum in a cold-adapted enzyme. Nature Communications 11, doi:10.1038/s41467-020-16341-2 (2020).

78 Karshikoff, A., Nilsson, L. \& Ladenstein, R. Rigidity versus flexibility: the dilemma of understanding protein thermal stability. FEBS Journal 282, 3899-3917, doi:10.1111/febs.13343 (2015).

79 Okafor, C. D. et al. Structural and dynamics comparison of thermostability in ancient, modern, and consensus elongation factor Tus. Structure 26, 118-129.e113, doi:10.1016/j.str.2017.11.018 (2018).

80 Gianese, G., Argos, P. \& Pascarella, S. Structural adaptation of enzymes to low temperatures. Protein Engineering, Design and Selection 14, 141-148, doi:10.1093/protein/14.3.141 (2001).

81 Santiago, M., Ramírez-Sarmiento, C. A., Zamora, R. A. \& Parra, L. P. Discovery, molecular mechanisms, and industrial applications of cold-active enzymes. Frontiers in Microbiology 7, 14081408, doi:10.3389/fmicb.2016.01408 (2016).

82 Spring, S. et al. Characterization of novel psychrophilic clostridia from an Antarctic microbial mat. International Journal of Systematic and Evolutionary Microbiology 53, 1019-1029, doi:10.1099/ijs.0.02554-0 (2003).

83 Wiegel, J., Kuk, S. U. \& Kohring, G. W. Clostridium thermobutyricum sp. nov., a moderate thermophile isolated from a cellulolytic culture, that produces butyrate as the major product. International Journal of Systematic Bacteriology 39, 199-204, doi:10.1099/00207713-39-2-199 (1989).

84 Szilágyi, A. \& Závodszky, P. Structural differences between mesophilic, moderately thermophilic and extremely thermophilic protein subunits: results of a comprehensive survey. Structure 8, 493-504, doi:10.1016/s0969-2126(00)00133-7 (2000). 